\title{
Effect of Silica Nanoparticle on the Quiescent and the Shear Induced Crystallization Behaviors of Poly(trimethylene terephthalate)
}

\author{
Yunku NAM, Kwang Bo SHIM, ${ }^{*}$ Seong Hun KIM, and Byoung Chul KIM ${ }^{\dagger}$ \\ Division of Applied Chemical Engineering, Hanyang University, 17 Haengdang, Seongdong, Seoul 133-791, Korea \\ ${ }^{*}$ Department of Ceramic Engineering, CPRC, Hanyang University, Seoul 133-791, Korea
}

(Received January 13, 2004; Accepted April 13, 2004; Published July 15, 2004)

\begin{abstract}
The isothermal crystallization behavior of poly(trimetylene terephthalate) (PTT) containing silica nanoparticles was investigated. The addition of silica nanoparticles increased the crystallization temperature of PTT by $20^{\circ} \mathrm{C}$ and notably decreased the size of the crystals. Higher silica nanoparticle content led to greater depression of equilibrium melting temperature. Quiescent isothermal crystallization in DSC capsule showed that silica nanoparticles acted as a nucleating agent for PTT and decreased the half time for crystallization. In the case of PTT containing silica nanoparticles 1 and $2 \mathrm{wt} \%$, however, little difference in the crystallization behavior was noticeable, suggesting that the silica content of $1 \mathrm{wt} \%$ is the critical level for nucleating. Isothermal crystallization under dynamic shear showed similar crystallization behavior with quiescent crystallization. In addition, higher shear rate accelerates the crystallization rate of PTT. However, X-Ray diffraction result revealed that the content of silica nanoparticles and application of shear had little effect on the resultant crystal structure. [DOI 10.1295/polymj.36.519]

KEY WORDS Poly(trimethylene terephthalate) (PTT) / Nanocomposites / Crystallization / Nucleation /
\end{abstract}

A variety of inorganic materials, such as glass fiber, talc, calcium carbonate, and clay minerals, have been widely used as additives or reinforcements to improve the thermal and mechanical properties of organic polymers. The key factors to enhance such properties include the size, shape, dispersion state, and interfacial adhesion of fillers in the polymer matrix. In recent years, the organic nanocomposites incorporating some nano-sized inorganic particles have attracted much attention as newly emerging materials. When compared with the conventional composites including submicron inorganic particles the nanocomposites are expected to give new and much improved properties even at the same composition. ${ }^{1-3}$ Some examples include increase of tensile modulus and strength, barrier properties, resistance to solvent, fire and heat, and optical transparency. ${ }^{4-6}$ Moreover, these improvements are expected to be obtained at much lower loading levels than the submicroparticles. The desired content of $1-10 \mathrm{wt} \%$ for nanoparticle is comparable with that of $25-40 \mathrm{wt} \%$ for submicronparticles in efficiency. ${ }^{7}$

Recently, poly(trimethylene terephthalte) (PTT) attracts much attention among polymer processors and is being intensively investigated as engineering thermoplastics and as a matrix for fiber-reinforced composite due to its good thermal and mechanical properties. ${ }^{8,9}$ In addition, PTT is predicted to obtain a large share in synthetic fiber market in the future because of its peculiar properties. Fumed silica nanoparticles manufactured by high-temperature hydrolysis of silicon tetrachloride in a flame has a spherical shape, extremely large surface areas, and a non-porous surface, which could promote physical contact with polymer matrix. ${ }^{10}$ Sumita et al. ${ }^{11}$ early pointed out the benefits of replacing silica microparticles by silica nanoparticles. It is expected that the fumed silica nanoparticle would improve the physical and mechanical properties of the polymer, which is closely related to the nucleating effect of the nanoparticle on the crystallization of the polymer. ${ }^{12,13}$

It is expected that the fumed silica nanoparticle promote the crystallization of PTT which exhibit rather a slow crystallization process. However, there is little research related to the crystallization behaviors of the fumed silica-filled PTT nanocomposites. This study investigates the physical properties of the fumed silica nanoparticle-filled PTT systems prepared by melt-compounding at various silica contents. The isothermal crystallization kinetics and morphology of the systems was examined and the isothermal crystallization behavior under dynamic shear was discussed for practical significance.

\section{EXPERIMENTAL}

\section{Materials and Preparation of the Nanocomposites}

PTT $\left(\eta_{\text {inh }}=0.92\right)$ was obtained from Hyosung (Korea). Silica nanoparticles (primary particle size:

${ }^{\dagger}$ To whom correspondence should be addressed (Tel: +82-2-2290-0494, Fax: +82-2-2297-4941, E-mail: bckim@ hanyang.ac.kr). 
$7 \mathrm{~nm}$; surface area: $390 \mathrm{~m}^{2} / \mathrm{g}$; purity: $99.8 \%$; hydroxyl group: $2.5 / \mathrm{nm}^{2}$ ) were purchased from Sigma-Aldrich Co. (USA). PTT was vacuum dried at $90^{\circ} \mathrm{C}$ for $24 \mathrm{~h}$ prior to experiment. The average particle size was performed using laser particle size analyzer (LS 230, Beckman Coulter, Inc.) and shown in Figure 1. Although the primary particle size of fumed silica nanoparticle is $7 \mathrm{~nm}$, the fumed silica nanoparticle has the mean size of $c a$. $109 \mathrm{~nm}$. It is because that it is easy to

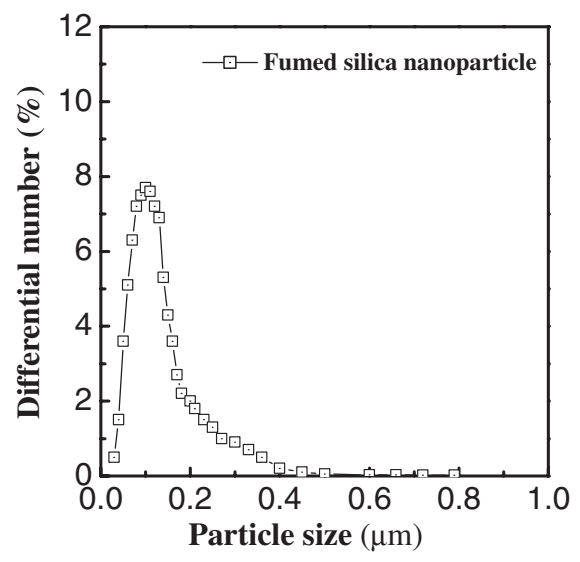

Figure 1. Average particle size distribution of fumed silica nanoparticle.

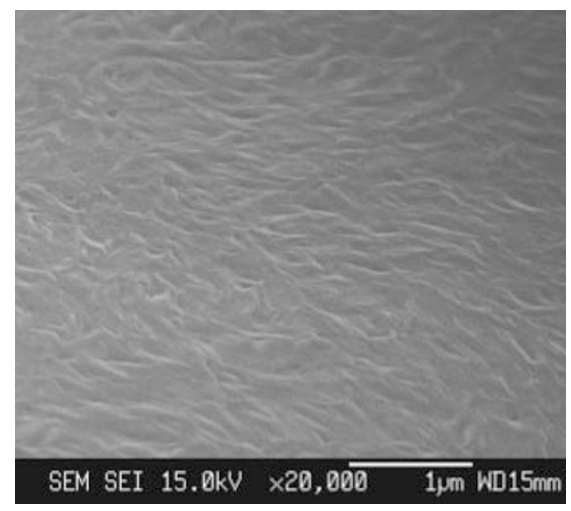

(a)

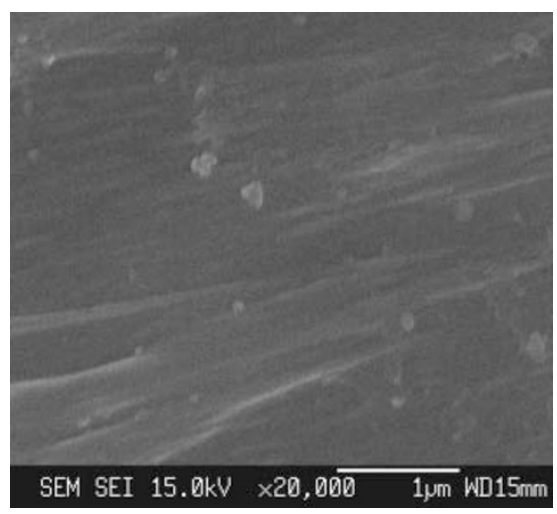

(c) form an aggregate and agglomerate while the agglomerate does not easily break down due to strong siloxane bonds at particle-particle interface.

PTT was crushed into a micro-sized powder and then premixed with silica nanoparticles before melt blending. Melt blending was carried out by an internal mixer (Haake Rheomix 600) at $250^{\circ} \mathrm{C}$. The mixing time and rotor speed were $5 \mathrm{~min}$ and $60 \mathrm{rpm}$, respectively. The content of silica nanoparticle was $0.5,1$, and $2 \mathrm{wt} \%$ for PTT, whose codes were PTT-0.5, PTT-1, and PTT-2, respectively. As can be seen in Figure 2, the silica nanoparticles are dispersed in the PTT matrix with silica content.

\section{Fractured Surface of the Nanocomposites}

Phase morphologies of the fracture surface of the nanocomposties were studied by Field Emission Scanning Electron Microscope (FE-SEM, JEOL, JSM6330F). Each fracture of the composites was prepared in liquid nitrogen. The samples were coated with gold-palladium alloy by using a coating sputter.

\section{Thermal Properties}

Thermal properties of the nanocomposites were investigated using DSC (PerkinElmer DSC7) over the

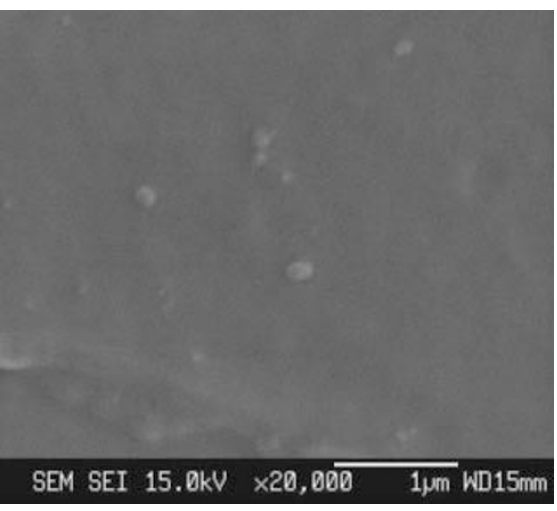

(b)

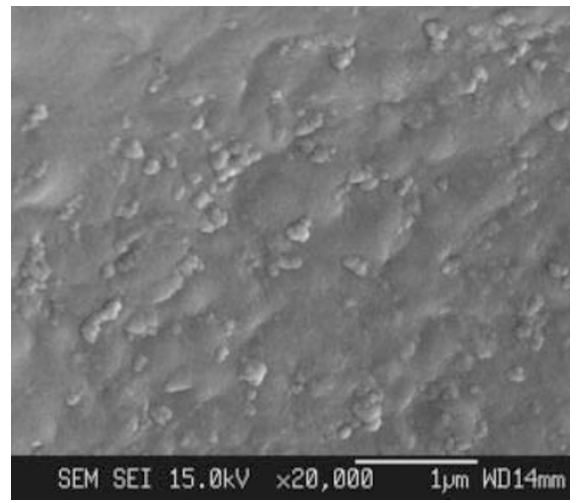

(d)

Figure 2. SEM images of fractured surface of pure PTT and PTT/silica nanocomposites: (a) pure PTT, (b) PTT-0.5, (c) PTT-1, and (d) PTT-2. 
temperature range of 10 to $250^{\circ} \mathrm{C}$ at the scan rate of $10^{\circ} \mathrm{C} / \mathrm{min}$ in nitrogen atmosphere. All the samples were isothermally crystallized in the temperature range from 190 to $210^{\circ} \mathrm{C}$ every $4{ }^{\circ} \mathrm{C}$. Prior to isothermal crystallization, the samples were cooled from molten state to the crystallization temperature at the rate of $200^{\circ} \mathrm{C} / \mathrm{min}$ and then kept at that temperature until the DSC trace returned to the calorimeter baseline.

\section{Isothermal Crystallization under Dynamic Shear}

The isothermal crystallization behavior under dynamic shear was investigated by ARES (Rheometric Scientific Inc.) at $202{ }^{\circ} \mathrm{C}$ at the time sweep mode. In ARES measurement the parallel-plate geometry with diameter $25 \mathrm{~mm}$ was adopted, whose gap was $1 \mathrm{~mm}$ at the strain level 5\%. The samples were melted at $250^{\circ} \mathrm{C}$. The initial gap was set to a value equivalent to final gap plus $50 \mu \mathrm{m}$. The excess sample was squeezed out by reducing the gap gradually, and then was carefully trimmed off. To eliminate the effect of residual stress and thermal history the set specimen was relaxed for $5 \mathrm{~min}$ at the temperature in nitrogen atmosphere, and then rapidly cooled to $202^{\circ} \mathrm{C}$.

\section{Crystalline Structure}

Wide angle X-Ray diffraction (WAXD) experiment was performed by Rigaku Corp. (D/MAX-2000) with Nickel filtered $\mathrm{Cu} K$ radiation of $40 \mathrm{kV}$ and $100 \mathrm{~mA}$. The specimens formed as a film were prepared by annealing at $170{ }^{\circ} \mathrm{C}$ for $24 \mathrm{~h}$ prior to measurement. Scanning experiment was carried out on the equator over the $2 \theta$ range of 5 to $45^{\circ}$ at the scan speed $5^{\circ} / \mathrm{min}$. WAXD pattern of the specimens crystallized under shear was also measured.

\section{Crystalline Morphology of the Nanocomposites}

A polarizing optical microscope equipped with a CCD camera was used to determine the quiescent and shear-induced crystallized morphology. The specimens of a thin film were sandwiched between microscope cover slips and melted at $250^{\circ} \mathrm{C}$ for $5 \mathrm{~min}$ to remove the thermal history, then rapidly cooled to the predetermined crystallization temperature. The crystallized specimens under dynamic shear were also measured.

\section{RESULTS AND DISCUSSION}

Thermal Properties and Crystal Structure of Pure PTT and PTT/Silica Nanocomposites

Figures $3 \mathrm{a}$ and $3 \mathrm{~b}$ show the DSC thermograms of the nanocomposties to compare the crystallization behavior of pure PTT and PTT/silica nanocomposites. The result of thermal analysis is given in Table I.

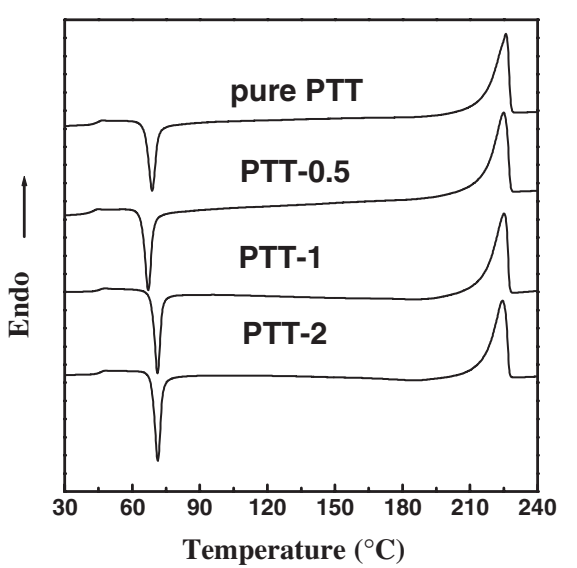

(a)

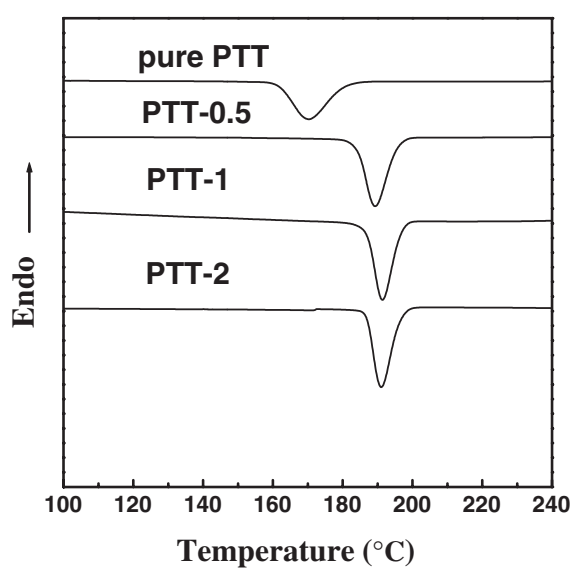

(b)

Figure 3. DSC thermograms of pure PTT and PTT/silica nanocomposites at $10^{\circ} \mathrm{C} / \mathrm{min}$ : (a) the 2 nd heating trace after quenching from the melt and (b) the cooling trace from the melt.

Table I. Thermal properties of pure PTT and PTT/silica nanocomposites

\begin{tabular}{lccccc}
\hline \multicolumn{1}{c}{ Sample } & $\begin{array}{c}T_{\mathrm{g}} \\
\left({ }^{\circ} \mathrm{C}\right)\end{array}$ & $\begin{array}{c}T_{\mathrm{c}} \\
\left({ }^{\circ} \mathrm{C}\right)\end{array}$ & $\begin{array}{c}T_{\mathrm{m}} \\
\left({ }^{\circ} \mathrm{C}\right)\end{array}$ & $\begin{array}{c}\Delta H_{\mathrm{f}} \\
(\mathrm{J} / \mathrm{g})\end{array}$ & $\begin{array}{c}\text { Crystallinity } \\
(\%)\end{array}$ \\
\hline Pure PTT & 43.1 & 170.2 & 225.9 & 57.8 & 39.4 \\
PTT-0.5 & 42.9 & 189.3 & 225.0 & 60.2 & 41.3 \\
PTT-1 & 45.3 & 191.4 & 225.0 & 58.1 & 39.6 \\
PTT-2 & 45.3 & 191.0 & 224.4 & 57.9 & 39.5 \\
\hline
\end{tabular}

The samples show only one exothermic peak in similar shape and similar glass transition temperature $\left(T_{\mathrm{g}}\right)$ and melting temperature $\left(T_{\mathrm{m}}\right)$ in error range. The value of heat of fusion has little difference between pure PTT and the nanocomposites. However, it should be noted that a remarkable difference between pure PTT and the nanocomposites is observed in the melt crystallization temperature $\left(T_{\mathrm{c}}\right)$. The crystallization temperature of the nanocomposites increases from 170 to $190^{\circ} \mathrm{C}$ and the width of the crystallization peaks narrows down when compared with pure PTT. Rong et al. have reported that the incorporation of sili- 
ca nanoparticles has no notable effect on the crystallization of polypropylene. ${ }^{14}$ However, Kim et al. investigating the isothermal crystallization of poly(ethylene naphthalate)/silica nanocomposites have shown that $T_{\mathrm{c}}$ has been increased with silica contents due to the characteristic of heterogeneous nucleation by silica nanopartilces. ${ }^{15}$ The same result has been observed in the report of Liu et al. studying poly(ethylene terephthalate) (PET)/silica nanocomposites. ${ }^{16}$ In this study, the increase of $T_{\mathrm{c}}$ is suggested that the silica nanoparticles result in the change from homogeneous nucleation to heterogeneous nucleation. In the case of heterogeneous nucleation resulting from the foreign materials, it is well known that $T_{\mathrm{c}}$ tends to increase due to the nucleating effect of the materials. ${ }^{7,17}$ However, there is little difference in $T_{\mathrm{c}}$ depending on the content change of silica nanoparticles.

It is important to measure the equilibrium melting temperature $\left(T_{\mathrm{m}}{ }^{0}\right)$ of polymer because the melting temperature crystallized at crystallization temperature $\left(T_{\mathrm{c}}\right)$ is dependent on the thermal history to some extent. Figure 4 shows the effect of isothermal crystallization temperature on the crystallization of the samples. The samples are cooled from the melt to $T_{\mathrm{c}}$ at the cooling rate of $200^{\circ} \mathrm{C} / \mathrm{min}$ and isothermally crystallized at the given temperature for $1 \mathrm{~h}$. Then, the samples are quenched to $10^{\circ} \mathrm{C}$ and reheated to $260^{\circ} \mathrm{C}$ at the rate of $10^{\circ} \mathrm{C} / \mathrm{min}$. With increasing the isothermal crystallization temperature the double melting behavior gets more notable for all PTT samples as shown in Figure 4. The double melting temperature was labeled $T_{\mathrm{m} 1}$ and $T_{\mathrm{m} 2}$. This melting behavior can be explained by recrystallizationremelting concept. ${ }^{18} T_{\mathrm{m} 1}$ is considered to be characteristic of the melting of the crystals formed at the given crystallization temperature. $T_{\mathrm{m} 2}$ results from the melting of crystals formed by recrystallization of imperfect crystals during the reheating stage. By these reasons, $T_{\mathrm{m} 1}$ is increased with increasing crystallization temperature and $T_{\mathrm{m} 2}$ is independent of the crystallization temperature. The $T_{\mathrm{m}}{ }^{0}$ of the samples can be determined by the Hoffman-Weeks equation, ${ }^{19}$ using extrapolation of a plot of $T_{\mathrm{m}} v s$. $T_{\mathrm{c}}$ to $T_{\mathrm{m}}=T_{\mathrm{c}}$.

$$
T_{\mathrm{m}}{ }^{0}-T_{\mathrm{m}}=M\left(T_{\mathrm{m}}{ }^{0}-T_{\mathrm{c}}\right)
$$

where, $M$ is a constant depending on the crystal dimension. $T_{\mathrm{m}}$ of the Eq 1 is correspondent to $T_{\mathrm{m} 1}$. Obtained $T_{\mathrm{m}}{ }^{0}$ of the samples according to this equation is

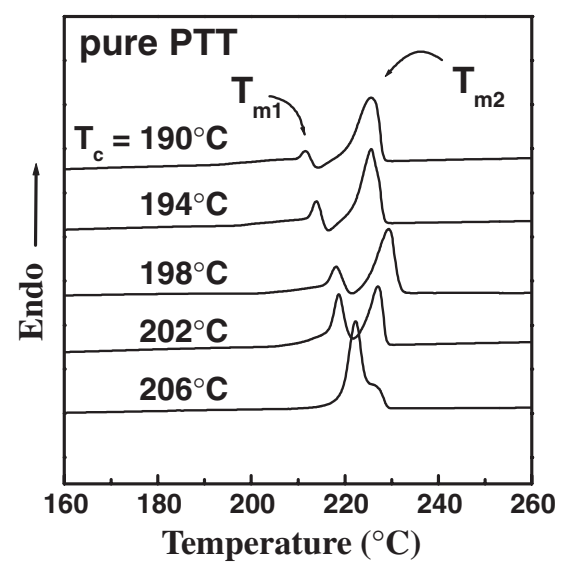

(a)

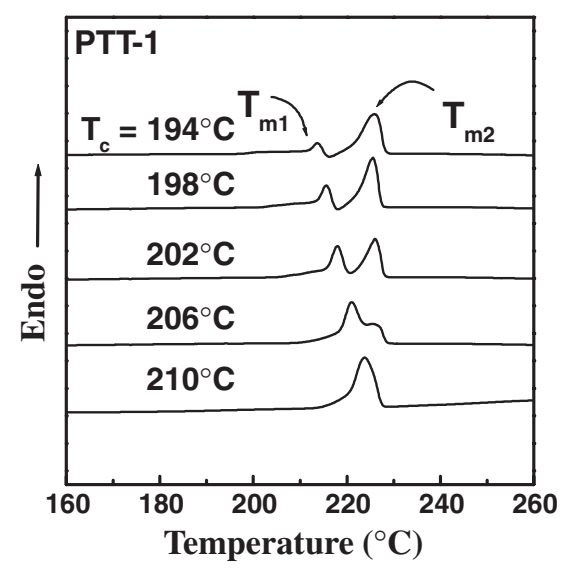

(c)

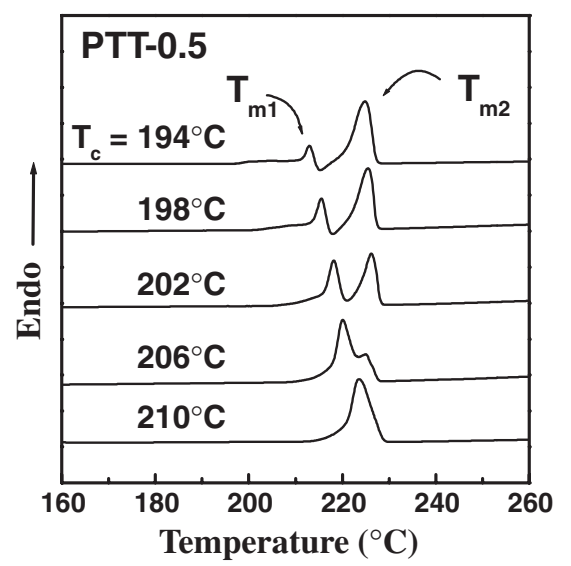

(b)

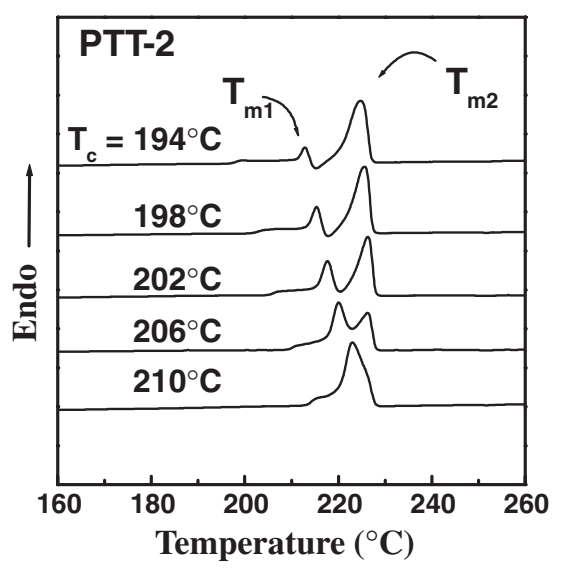

(d)

Figure 4. Double melting behavior of the samples: (a) pure PTT, (b) PTT-0.5, (c) PTT-1, and (d) PTT-2. 


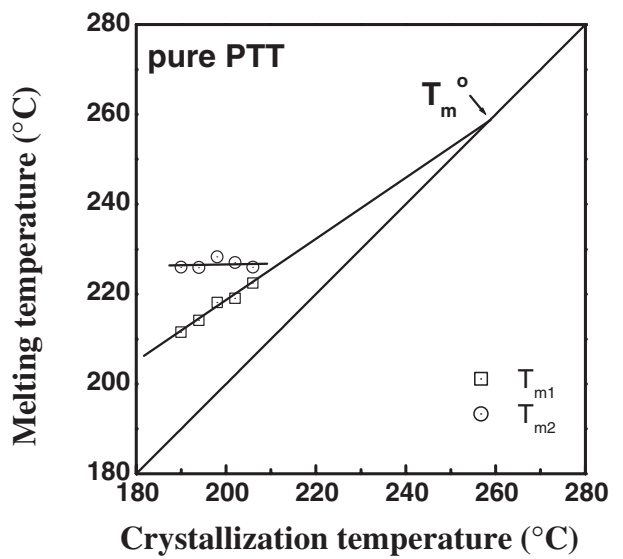

(a)

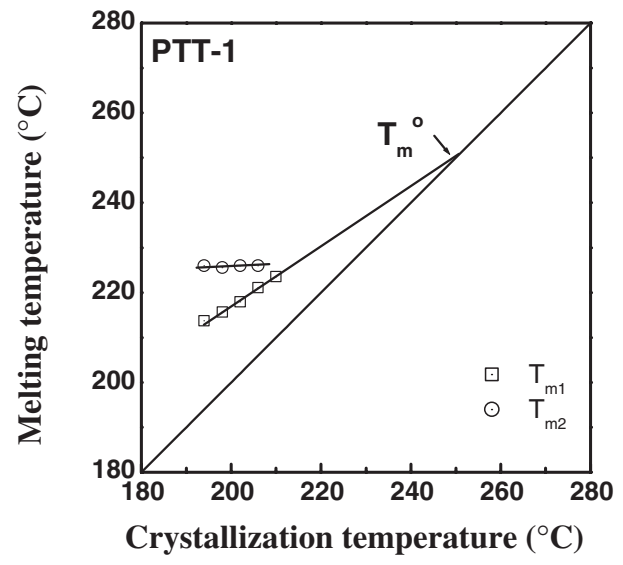

(c)

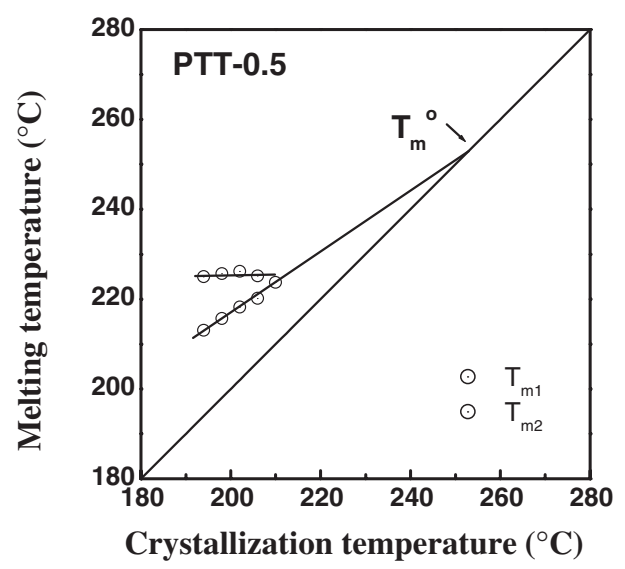

(b)

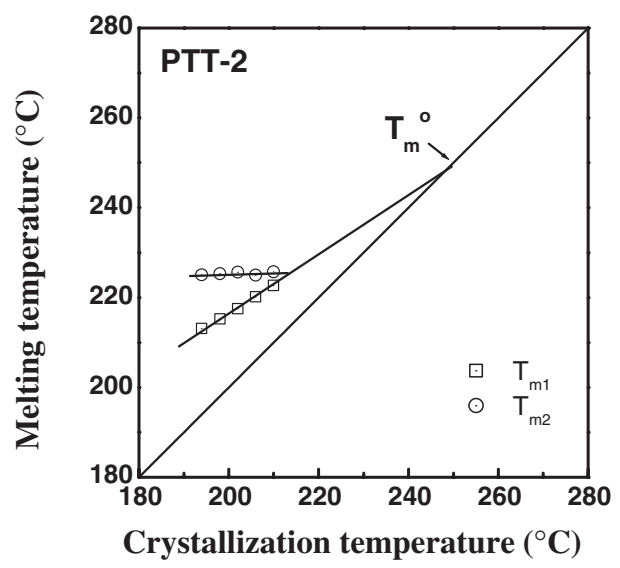

(d)

Figure 5. Hoffman-Week's plot for the samples. Plot of melting point, $T_{\mathrm{m} 1}$ and $T_{\mathrm{m} 2}$, against crystallization temperature, $T_{\mathrm{c}}$ : (a) pure PTT, (b) PTT-0.5, (c) PTT-1, and (d) PTT-2.

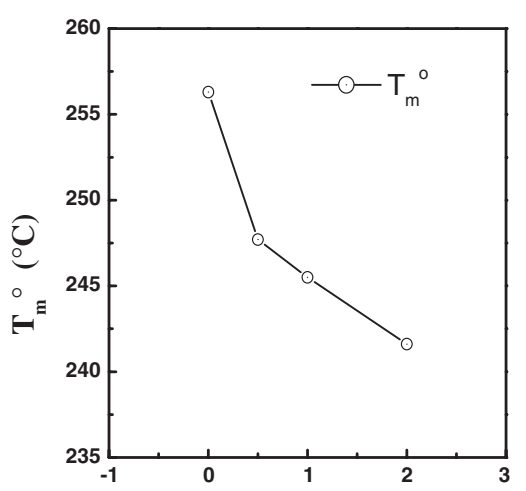

Content of the silica nanoparticle $(w \mathrm{t} \%)$

Figure 6. Variation of $T_{\mathrm{m}}{ }^{0}$ of pure PTT and PTT/silica nanocomposites with silica nanoparticle content.

plotted in Figure 5, respectively. Figure 6 shows the effect of the usage level of silica nanoparticles on the $T_{\mathrm{m}}{ }^{0}$ of PTT. $T_{\mathrm{m}}{ }^{0}$ is decreased as the nanoparticle content is increased, suggesting that the silica nanopartilces reduce the lamella thickness of PTT.

Another possibility of reducing $T_{\mathrm{m}}$ may be change in crystal structure by incorporation of a foreign material. To trace it the wide angle X-Ray diffraction

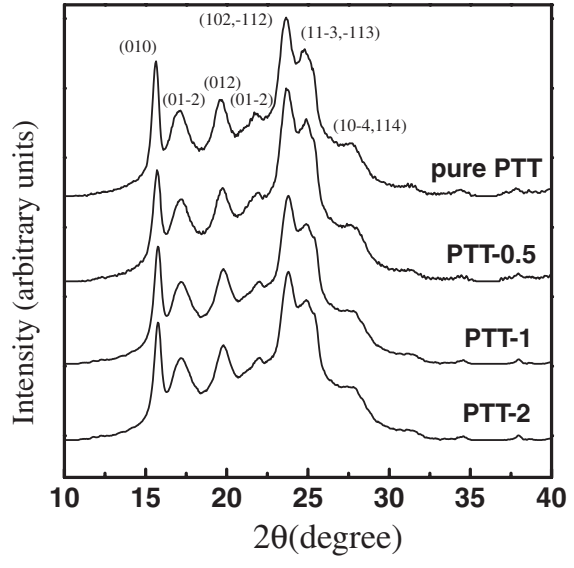

Figure 7. WAXD patterns of pure PTT and PTT/silica nanocomposites crystallized at $170^{\circ} \mathrm{C}$ for $24 \mathrm{~h}$.

(WAXD) patterns of the samples are shown in Figure 7. The peaks on the WAXD patterns of pure PTT, 16.0, 17.35, 19.9, 22.0, 23.85, and $25.2^{\circ}$, are assigned as $(010),(01 \overline{2}),(012),(10 \overline{2}),(102, \overline{1} 12)$, $(11 \overline{3}, \overline{1} 13)$, and $(10 \overline{4}, 114)$, respectively. These crystal lattices are unique for PTT. ${ }^{20}$ The patterns of the nanocomposites are same to those of pure PTT and 
there is no new peak and shift. This result indicates that silica nanoparticles have little effect on crystal lattice of PTT. Consequently, It is suggested that the reduction in $T_{\mathrm{m}}{ }^{0}$ is largely ascribed to the fact that majority of the crystals in the nanocomposites may have very thin lamella particularly at higher nanoparticle content.

The Quiescent Isothermal Crystallization of Pure PTT and PTT/Silica Nanocomposites

The weight fraction of the crystallized polymer at time $t, X(t)$, is calculated by Eq 2 .

$$
X(t)=\int_{0}^{t} \frac{\mathrm{d} H}{\mathrm{~d} t} \mathrm{~d} t / \int_{0}^{\infty} \frac{\mathrm{d} H}{\mathrm{~d} t} \mathrm{~d} t
$$

where, the first and the second integrals are the heat generated at time $t$ and the total heat generated up to the end of crystallization, respectively. The plot, the relative crystallinity of the samples as a function of time, is shown in Figure 8. The isothermal crystallization of the nanocomposites as well as pure PTT is completed within one hour. Since the respective $T_{\mathrm{c}}$ of pure PTT and PTT/silica nanocomposites is $c a .170$ and $190^{\circ} \mathrm{C}$ the samples need longer times to complete crystallization with increasing the crystallization temperature. The half-time of crystallization $\left(t_{1 / 2}\right)$ is defined as the time required for half of the final crystallinity to develop. The variation of $t_{1 / 2}$ and $\log \left(t_{1 / 2}\right)^{-1}$ with the degree of supercooling $\left(\Delta T=T_{\mathrm{m}}{ }^{0}-T_{\mathrm{c}}\right)$ is shown in Figure 9. The value of $t_{1 / 2}$ is strongly dependent on $\Delta T$. The crystallization rate of the nanocomposites is faster than that of pure PTT at the same $\Delta T$. The crystallization rate between the nanocomposites looks more and more noticeable under $\Delta T=$ $45^{\circ} \mathrm{C}$. The slopes on the plot of $\log \left(t_{1 / 2}\right)^{-1}$ against $\Delta T$ have similar values irrespective of silica content, indicating that the crystallization process of all specimens is almost the same. Overall crystallization rate of PTT-1 is higher than that of other nanocomposites particularly at low $\Delta T$ region. After PTT-1, PTT-2, PTT-0.5, and pure PTT follow. Chisholm et al. have shown that layered silicate nanopartilces have not enhanced the rate of crystallization of poly(butylene terephthalate) (PBT) and have decreased the crystallization rate, suggesting that clay nanoparticles are not effective nucleating agents for PBT crystallization. ${ }^{21}$

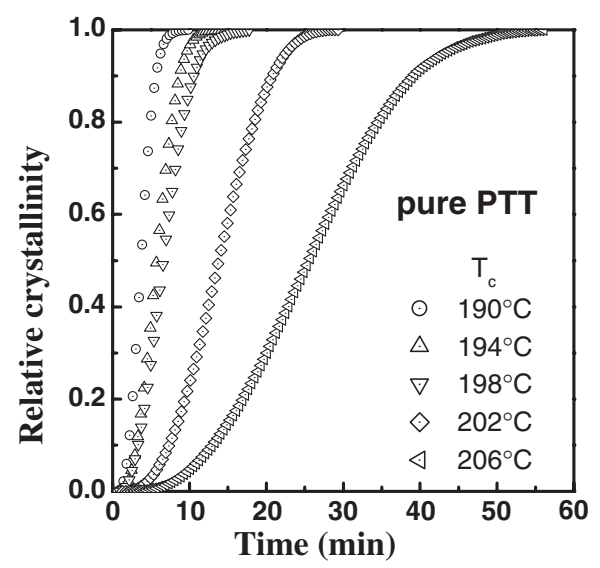

(a)

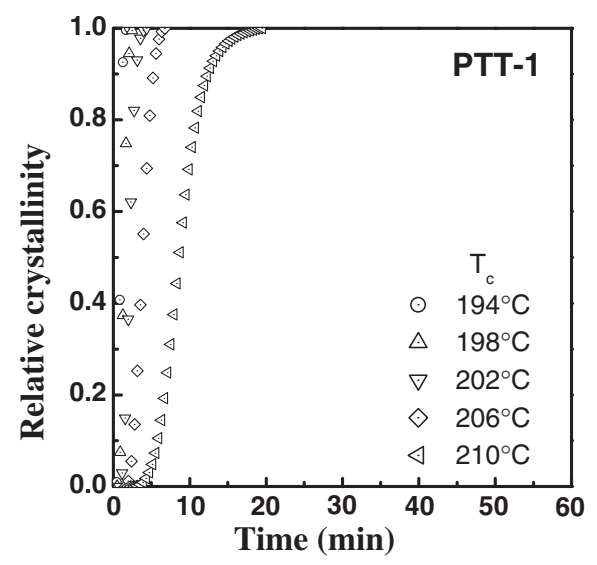

(c)

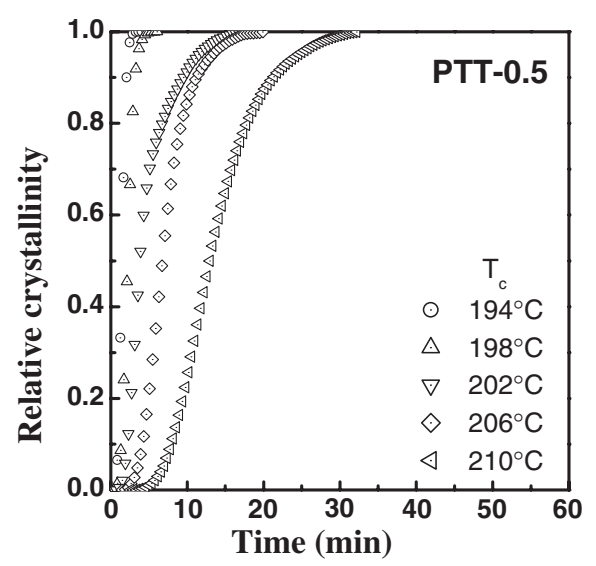

(b)

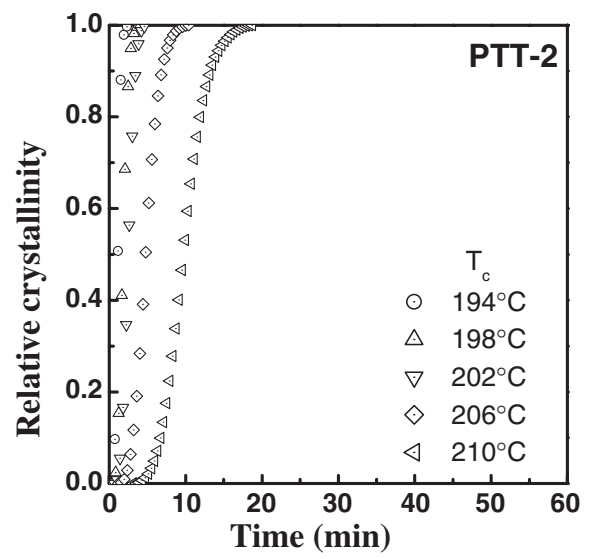

(d)

Figure 8. Variation of relative crystallinity with time for the samples crystallized at various temperatures: (a) pure PTT, (b) PTT-0.5, (c) PTT-1, and (d) PTT-2. 


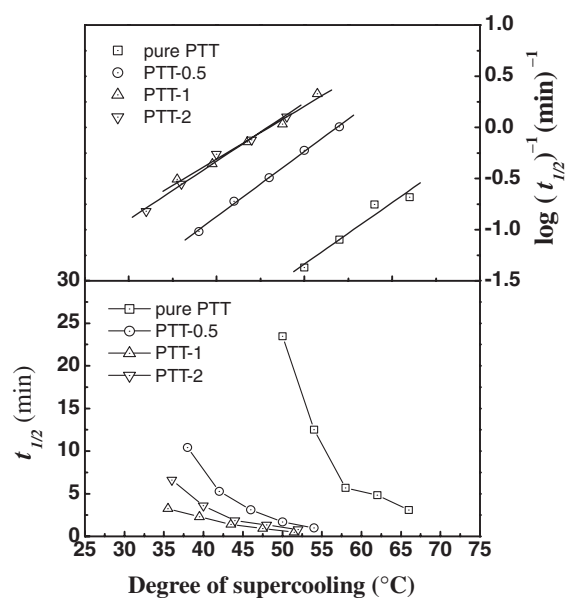

Figure 9. Variation of half time of crystallization $\left(t_{1 / 2}\right)$ and $\log \left(t_{1 / 2}\right)^{-1}$ of pure PTT and PTT/silica nanocomposites with the degree of supercooling.

However, the silica nanoparticles result in some changes of PTT crystallization in PTT/silica system. This phenomenon showing the increase of crystallization rate coincides in that observed for PET-based nanocomposites. ${ }^{22,23}$ This verifies that silica nanoparticles promote the nucleating and crystallization of PTT. Induction time to crystallization of the samples is also increased with increasing $T_{\mathrm{c}}$. Owing to the nucleating effect the induction time of the nanocomposites is much shorter than pure PTT with increasing the silica content as shown in Figure 10. However the induction time seems to have little relation between PTT-1 and PTT-2. The reversed phenomenon between PTT-1 and PTT-2 will be treated at the end of this section.

The isothermal crystallization kinetics of pure PTT and PTT/silica nanocomposites is analyzed on the basis of the Avrami equation. ${ }^{24,25}$

$$
\log [-\ln (1-X t)]=\log k+n \log t
$$

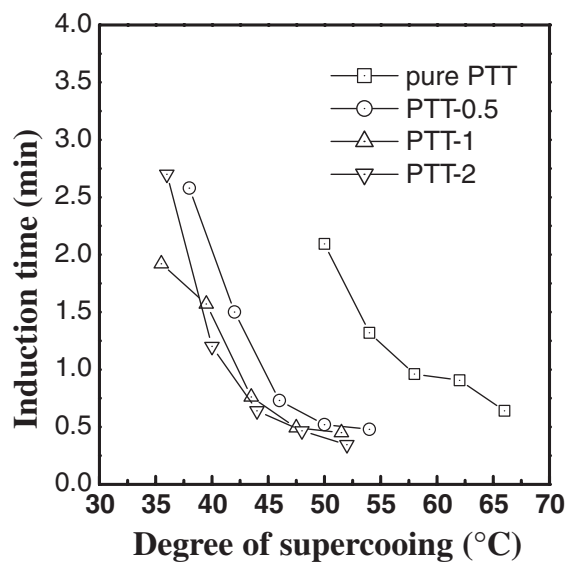

Figure 10. Variation of induction time of pure PTT and PTT/ silica nanocomposites with the degree of supercooling.
Table II. Avrami plot of pure PTT and PTT/silica nanocomposties

\begin{tabular}{|c|c|c|c|}
\hline Sample & $\begin{array}{c}T_{\mathrm{c}} \\
\left({ }^{\circ} \mathrm{C}\right)\end{array}$ & $n$ & $K$ \\
\hline \multirow{5}{*}{ Pure PTT } & 190 & 3.2 & $102.0 \times 10^{-4}$ \\
\hline & 194 & 3.0 & $44.8 \times 10^{-4}$ \\
\hline & 198 & 2.7 & $33.8 \times 10^{-4}$ \\
\hline & 202 & 3.0 & $2.9 \times 10^{-4}$ \\
\hline & 206 & 2.8 & $0.9 \times 10^{-4}$ \\
\hline \multicolumn{4}{|c|}{ Average value of $n: 2.9$} \\
\hline \multirow{5}{*}{ PTT-0.5 } & 190 & 4.1 & $140.1 \times 10^{-3}$ \\
\hline & 194 & 3.7 & $35.5 \times 10^{-3}$ \\
\hline & 198 & 2.7 & $11.6 \times 10^{-3}$ \\
\hline & 202 & 3.0 & $11.3 \times 10^{-3}$ \\
\hline & 206 & 3.5 & $0.8 \times 10^{-3}$ \\
\hline \multicolumn{4}{|c|}{ Average value of $n: 3.4$} \\
\hline \multirow{5}{*}{ PTT-1 } & 190 & 5.0 & $1031.1 \times 10^{-3}$ \\
\hline & 194 & 4.4 & $145.9 \times 10^{-3}$ \\
\hline & 198 & 4.3 & $24.9 \times 10^{-3}$ \\
\hline & 202 & 5.6 & $1.5 \times 10^{-3}$ \\
\hline & 206 & 4.5 & $0.5 \times 10^{-3}$ \\
\hline \multicolumn{4}{|c|}{ Average value of $n: 4.7$} \\
\hline \multirow{5}{*}{ PTT-2 } & 190 & 4.3 & $385.4 \times 10^{-3}$ \\
\hline & 194 & 4.0 & $66.8 \times 10^{-3}$ \\
\hline & 198 & 4.2 & $14.4 \times 10^{-3}$ \\
\hline & 202 & 4.1 & $1.2 \times 10^{-3}$ \\
\hline & 206 & 4.6 & $0.01 \times 10^{-3}$ \\
\hline \multicolumn{4}{|c|}{ Average value of $n: 4.2$} \\
\hline
\end{tabular}

where, $X(t)$ is the weight fraction of crystallinity, $n$ is the Avrami exponent, $k$ is the overall kinetic rate constant, and $t$ is the time of crystallization. Both of the values of $k$ and $n$ depend on the mechanism of nucleation as well as growth geometry. The values of $k$ and $n$ can be obtained by the double logarithmic plot of Avrami. The result for pure PTT at different crystallization temperatures is given in Table II. The value of $k$ is extremely sensitive to temperature, which determines the nucleation and growth processes. The overall rate constant of crystallization is higher at lower $T_{\mathrm{c}}$ over the temperature range examined. The value of $n$ varies with the nanoparticle content. Average value of $n$ of pure PTT is $c a .2 .9$ irrespectively of $T_{\mathrm{c}}$, indicating that both nucleation and growth mechanism are similar over the crystallization temperature range investigated. This value agrees with the previous report by Huang and Chang. ${ }^{26}$ On the other hand, PTT-0.5, PTT-1, and PTT-2 have the average value of $n$ of $3.4,4.7$, and 4.2 , respectively. This indicates that the dimensionality of crystal growth is increased as the content of the silica nanoparticle is increased probably due to the nano-size effect giving rise to heterogeneous nucleation. In general, a heterogeneous nucleation path makes use of foreign preexisting surfaces to reduce the free energy opposing primary nucleation. 
This reduced free energy meaning of the lowered free enthalpy of nucleation finally leads to faster nucleation. Because nano-sized silica has a noticeable apparent surface area per unit weight it seems to affect greatly the crystallization kinetic of PTT more than micro-sized. On the other hand, the increase of seeds volume leads to increase the number of the nuclei. However, it is general that over a limit of seeds volume the increase of nuclei is not linearly despite much addition of seeds. ${ }^{27}$ It is thus suggested that not only the nucleating effect of the silica nanoparticle but also the dimensionality of crystal growth reach the maximum when the content of silica nanoparticles are $1 \mathrm{wt} \%$ in this study. This accounts for the reason why the crystallization rate of PTT- 1 is faster that that of PTT-2, why the induction time of PTT-1 and PTT-2 shows little deference, and why the Avrami exponent of the samples shows variation with silica content. Similar phenomenon is also observed in the dynamic isothermal crystallization.

\section{The Shear-induced Crystallization of Pure PTT and PTT/Silica Nanocomposites}

It is well recognized that application of dynamic shear to the crystallizing systems has a great effect on the crystallization kinetics. Typical example for this is the shear-induced crystallization of polymers. Fu et al. have developed in situ SAXS technique with synchrotron radiation that is suitable for monitoring morphological changes during shear induced crystallization in real time. ${ }^{28}$ However, shear induced crystallization behavior also can be examined by using some rheological instruments. ${ }^{29,30}$ Isothermal crystallization experiment on the PTT and the nanocomposites is carried out by some rotational type rheometers to trace the shear induced crystallization behavior of the samples. To examine the effect of the extent of shear, the rheological measurement by the rotational rheometer is frequently performed at several different frequencies. As might be imagined increase of storage modulus $\left(G^{\prime}\right)$ on the time-sweep plot is indicative of increase of crystallinity and the equilibrium value of $G^{\prime}$ on the plot represents the ceiling value, which means crystallization is fully accomplished.

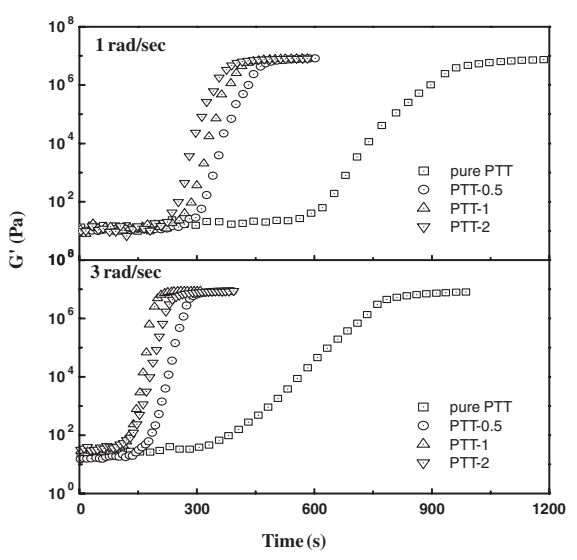

Figure 11. Variation of storage modulus $\left(G^{\prime}\right)$ with time at 1 and $3 \mathrm{rad} / \mathrm{s}$ at $202{ }^{\circ} \mathrm{C}$ for pure PTT and PTT/silica nanocomposites.

Fu et al. have shown that the overall orientation of the polymer chains has been improved and a faster crystallization rate has been obtained with the addition of nanostructured polyhedral oligomeric silsesquioxane (POSS). Moreover, they have revealed that higher POSS concentrations have resulted in faster crystallization rates during shear. ${ }^{28}$ Their results are similar with those of ARES in this study. To estimate the crystallization process of pure PTT and the nanocomposites variation of $G^{\prime}$ with time at frequencies of 1 and $3 \mathrm{rad} / \mathrm{s}$ at $202^{\circ} \mathrm{C}$ was measured by a rotational rheometer, ARES. The result is shown in Figure 11. Firstly, the value of $G^{\prime}$ increases sharply after taking some induction time. Secondly, the induction time is shorter at higher frequency. Thirdly, introducing silica nanoparticle greatly diminishes the induction time and accelerates crystallization, which comes from the nucleating effect of the nanoparticle. Existence of induction time reflects that it takes some time for randomly entangled polymer chains to transform to the aligned lattice. The shorter induction time at higher frequency is because higher shear rate gives rise to higher molecular orientation, which offers more favorable conditions for crystallization.

Table III summarizes the results on induction time and overall crystallization time measured by DSC and ARES. The silica content has an effect on induction

Table III. Induction time and overall crystallization time of pure PTT and PTT/silica nanocomposites during quiescent and shear induced crystallization at $202^{\circ} \mathrm{C}$

\begin{tabular}{|c|c|c|c|c|c|c|}
\hline \multirow{3}{*}{ Sample } & \multicolumn{3}{|c|}{ Induction time (s) } & \multicolumn{3}{|c|}{ Overall crystallization time (s) } \\
\hline & \multirow{2}{*}{ DSC } & \multicolumn{2}{|c|}{ ARES } & \multirow{2}{*}{ DSC } & \multicolumn{2}{|c|}{ ARES } \\
\hline & & $1 \mathrm{rad} / \mathrm{s}$ & $3 \mathrm{rad} / \mathrm{s}$ & & $1 \mathrm{rad} / \mathrm{s}$ & $3 \mathrm{rad} / \mathrm{s}$ \\
\hline Pure PTT & 79 & 490 & 290 & 1890 & 610 & 590 \\
\hline PTT-0.5 & 44 & 200 & 100 & 942 & 350 & 230 \\
\hline PTT-1 & 46 & 200 & 70 & 270 & 280 & 190 \\
\hline PTT-2 & 38 & 180 & 70 & 292 & 300 & 230 \\
\hline
\end{tabular}


time and crystallization rate of PTT up to $1 \mathrm{wt} \%$. It is noted that the nanocomposites containing between 1 and $2 \mathrm{wt} \%$ silica nanoparticles show little deference in the induction time and the crystallization rate, the same trend as the DSC experiment.

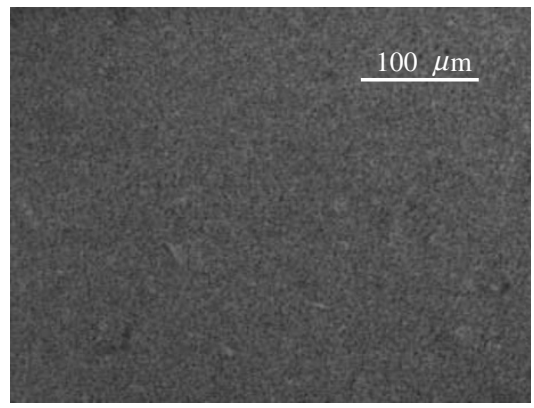

(a)

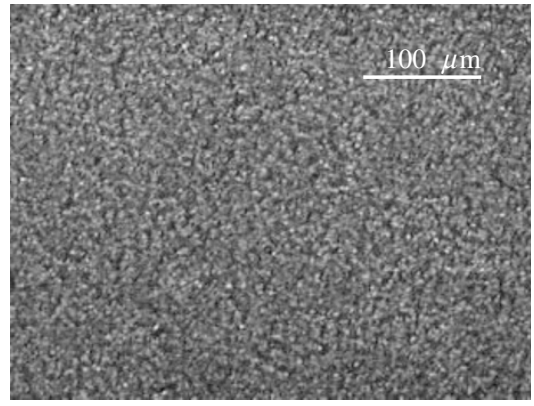

(c)
Morphology of Crystals Formed by Quiescent Crystallization

Figures 12 and 13 show the crystalline morphology of crystals of pure PTT and PTT/silica nanocomposites isothermally grown at $202^{\circ} \mathrm{C}$ for $2 \mathrm{~min}$ and $1 \mathrm{~h}$,

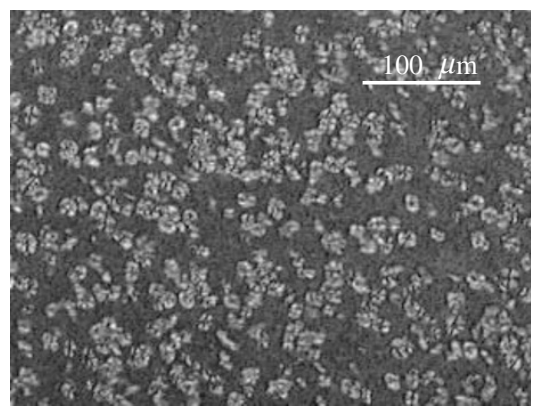

(b)

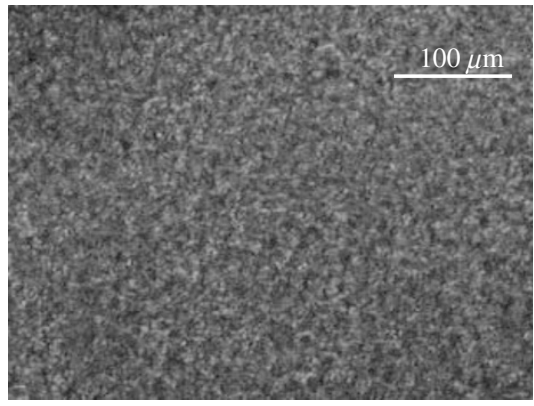

(d)

Figure 12. Polarizing optical micrographs of pure PTT and PTT/silica nanocomposites crystallized at $202^{\circ} \mathrm{C}$ for $2 \mathrm{~min}$ : (a) pure PTT, (b) PTT-0.5, (c) PTT-1, and (d) PTT-2.

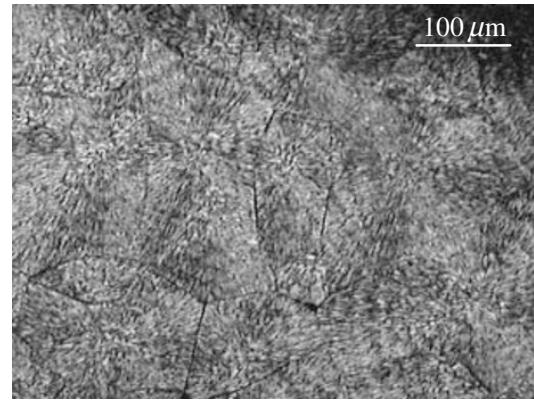

(a)

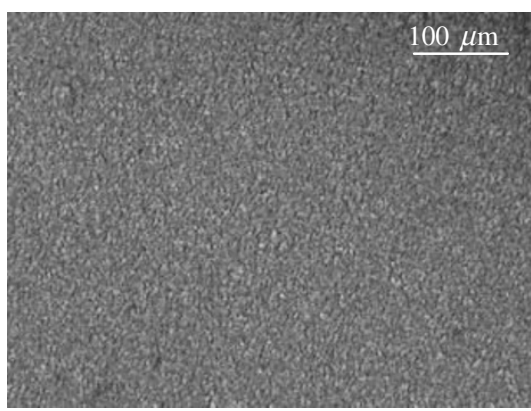

(c)

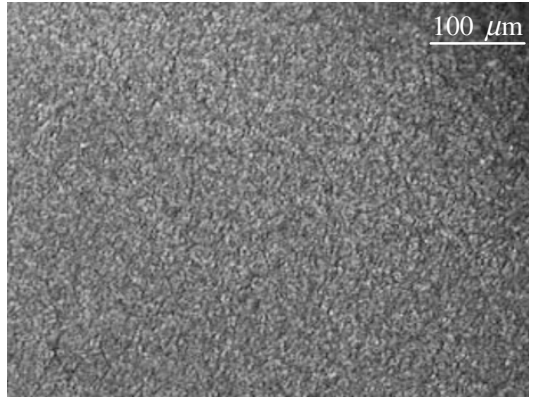

(b)

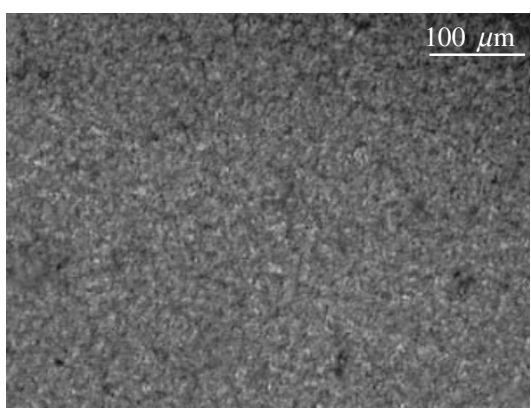

(d)

Figure 13. Polarizing optical micrographs of pure PTT and PTT/silica nanocomposites fully crystallized at $202^{\circ} \mathrm{C}$ : (a) pure PTT, (b) PTT-0.5, (c) PTT-1, and (d) PTT-2. 
respectively. Figure 13 shows the fully developed crystalline morphology because there is little change in morphology after $1 \mathrm{~h}$. For the first $2 \mathrm{~min}$, pure PTT does not produce any observable crystallites but the nanocomposites do as shown in Figure 12. Comparing Figure 12 with Figure 13, it is clear that the spherulites of PTT-0.5 keeps on growing after

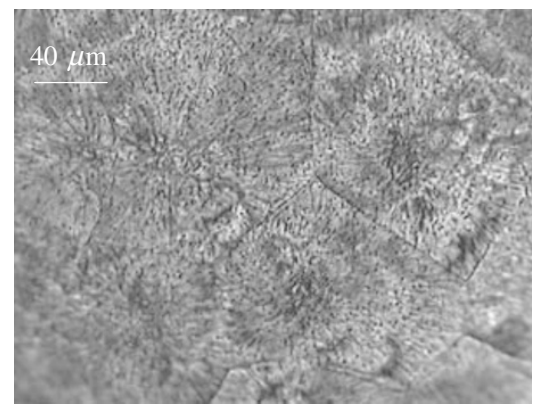

(a)

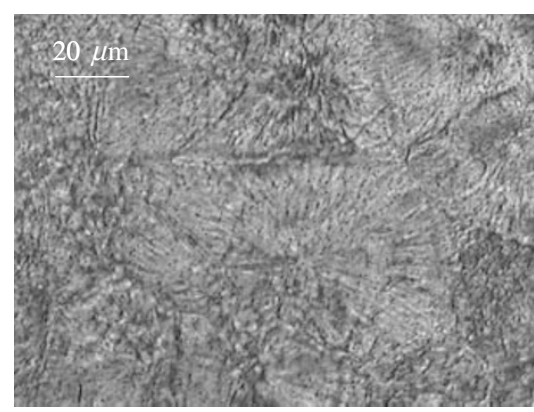

(c)

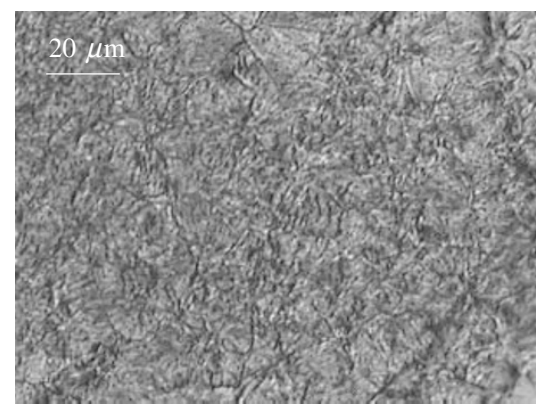

(e)

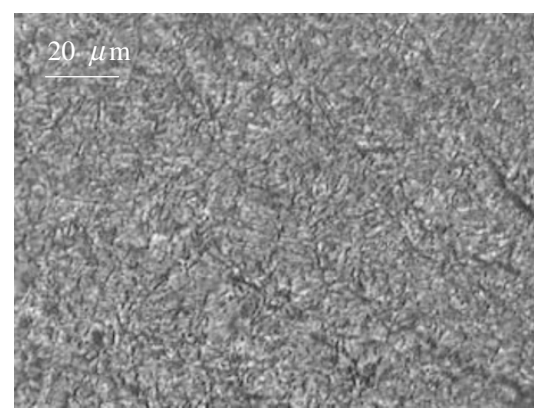

(g)
2 min. In the cases of PTT-1 and PTT-2, however, the growth of the spherulites seems to be completed because the resultant crystalline morphology in Figure 12 is almost the same that is shown for the fully crystallized morphology shown in Figure 13. The pure PTT and PTT- 0.5 produce spherulites of average diameters of $c a$. 140 and $40 \mu \mathrm{m}$, respectively.

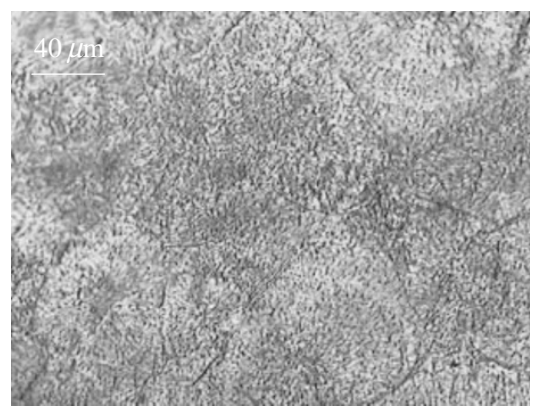

(b)

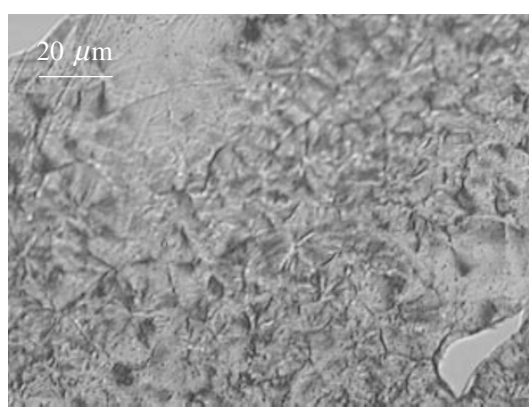

(d)

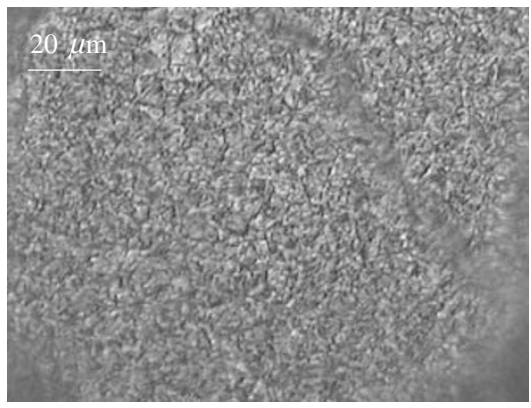

(f)

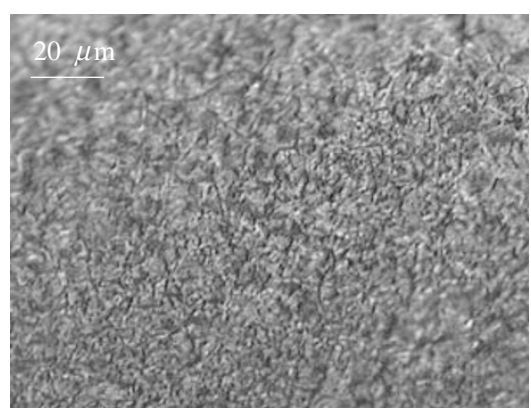

(h)

Figure 14. The polarizing optical micrographs of pure PTT and PTT/silica nanocomposites isothermally crystallized at 1 and $3 \mathrm{rad} / \mathrm{s}$ at $202^{\circ} \mathrm{C}$. (a) pure PTT at $1 \mathrm{rad} / \mathrm{s}$ (b) pure PTT at $3 \mathrm{rad} / \mathrm{s}$, (b) PTT-0.5 at $1 \mathrm{rad} / \mathrm{s}$, (c) PTT-0.5 at $3 \mathrm{rad} / \mathrm{s}$, (d) PTT-1 at $1 \mathrm{rad} / \mathrm{s}$, (e) PTT-1 at $3 \mathrm{rad} / \mathrm{s}$, (f) PTT-2 at $1 \mathrm{rad} / \mathrm{s}$, and (g) PTT-2 at $3 \mathrm{rad} / \mathrm{s}$. 


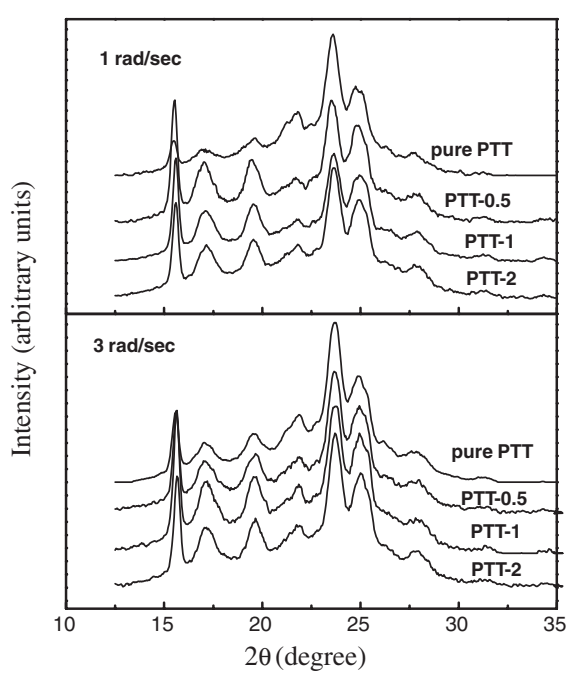

Figure 15. WAXD patterns of pure PTT and PTT/silica nanocomposites fully crystallized at 1 and $3 \mathrm{rad} / \mathrm{s}$ at $202^{\circ} \mathrm{C}$.

However, the other nanocomposites do not produce any noticeable spherulite. Thus, it is evident that silica nanoparticles play the role of nucleating agent in the quiescent crystallization process of PTT.

\section{Morphology of Crystals Isothermally Crystallized un- der Dynamic Shear}

Figure 14 shows the spherulites of pure PTT and PTT/silica nanocomposites crystallized at different shear rates at $202^{\circ} \mathrm{C}$. At the frequency of $1 \mathrm{rad} / \mathrm{s}$ the pure PTT produces spherulites whose boundaries are clearly defined. However, it produces spherulites with less clear boundaries at $3 \mathrm{rad} / \mathrm{s}$. Increasing the nanoparticle content also makes the boundaries between spherulites more unclear. In addition, increasing frequency reduces the size of spherulites. PTT-0.5 and PTT-1 also exhibit similar behavior. These phenomena support the result of ARES experiment which states that higher shear rate produces spherulites of smaller size. Figure 15 shows the WAXD pattern of pure PTT and the nanocomposites crystallized at the frequency of 1 and $3 \mathrm{rad} / \mathrm{s}$. When compared with the WAXD pattern of the same samples in Figure 7, which are quiescently crystallized, there is little change in X-Ray pattern. This suggests that the incorporation of the silica nanoparticles and application of shear do not affect the crystal structure of PTT.

\section{CONCLUSIONS}

The silica nanoparticle has a profound effect on the crystallization behavior and resultant crystalline morphology of PTT. Up to the loading level $1 \mathrm{wt} \%$ introducing silica nanopartilces reduced the induction time for crystallization and increased the crystallization rate. However, the deference between 1 and 2 wt $\%$ of silica nanoparticles is not clear, suggesting that the silica content of $1 \mathrm{wt} \%$ is the critical level for nucleating. On the whole, increasing the shear rate also reduced the induction time for crystallization and increased the crystallization rate. However, the content of silica nanoparticles and the extent of shear had little effect on the resultant crystal structure.

Acknowledgment. This research was supported by grant No. HY-2003-NT-002 from Hanyang University, Korea.

\section{REFERENCES}

1. D. Smoug, Mod. Plast., 2, 28 (1998).

2. Y. Kurokawa, H. Yasudo, M. Kashiwagi, and A. Oyo, J. Mater. Sci. Lett., 16, 1670 (1997).

3. M. Kawasumi, N. Hasegawa, M. Kato, A. Usuki, and A. Okada, Macromolecules, 30, 6333 (1997).

4. E. Giannelis, Adv. Mater., 8, 19 (1996).

5. Y. Kojima, A. Usuki, M. Kawasumi, A. Okada, Y. Fukushima, T. Kurauchi, and O. Kamigaito, J. Mater. Res., 95, 940 (1993).

6. C. J. Brinker and G. W. Scherer, "Sol-Gel Science; The Physics and Chemistry of Sol-Gel Processing," Academic Press, San Diego, CA, 1990.

7. C. Saujanya and S. Radhakrishnam, Polymer, 42, 6723 (2001).

8. K. Tsumashima and M. Suzuki, Japan Patent, 08:104, 763 (1996).

9. K. Dangayach, H. Chuah, W. Gergen, P. Dalton, and F. Smith, "Plastics-Saving Planet Earth," Proceedings of the 55th ANTEC Conference 2097, Toronto, ON, April 27-May 2, 1997.

10. H. Barthel, M. Heinemann, M. Stintz, and B. Wessely, Part. Part. Syst. Charact., 16, 169 (1999).

11. M. Sumita, T. Shizuma, K. Miyasaka, and K. Ishikawa, J. Macromol. Sci., Part B: Phys., 22, 601 (1983).

12. M. R. Mackley and A. Keller, Polymer, 14, 16 (1973).

13. A. Peterlin, Polym. Eng. Sci., 16, 126 (1976).

14. M. Z. Rong, M. Q. Zhang, Y. X. Zheng, H. M. Zeng, R. Walter, and K. Friedrich, Polymer, 42, 3301 (2001).

15. S. H. Kim, S. H. Ahn, and T. Hirai, Polymer, 44, 5625 (2003).

16. W. Liu, X. Tian, P. Cui, Y. Li, K. Zheng, and Y. Yang, J. Appl. Polym. Sci., 91, 1229 (2004).

17. H. N. Beck and H. D. Ledbetter, J. Appl. Polym. Sci., 9, 2131 (1965).

18. R. L. Scherrenberg, H. Reynaers, C. Gondard, and P. A. M. Steeman, J. Polym. Sci., Polym. Phys. Ed., 32, 111 (1994).

19. J. D. Hoffman and J. J. Weeks, J. Res. Natl. Bur. Stand. A, 66, 13 (1962).

20. B. Wang, C. Y. Li, J. Hanzlicek, S. Z. D. Cheng, P. H. Geil, J. Grebowicz, and R. M. Ho, Polymer, 42, 7171 (2001).

21. B. J. Chisholm, R. B Moore, G. Barber, F. Khouri, A. Hempstead, M. Larsen, E. Olson, J. Kelley, G. Balch, and J. Caraher, Macromolecules, 35, 5508 (2002).

22. Y. Kojima, A. Usuki, M. Kawasumi, A. Okada, T. Kurauchi, 
O. Kamigaito, and K. Kaji, J. Polym. Sci., Polym. Phys. Ed., 33, 1039 (1995).

23. Y. Ke, C. Long, and Z. Qi, J. Appl. Polym. Sci., 71, 1139 (1999).

24. M. Avrami, J. Chem. Phys., 8, 212 (1939).

25. M. Avrami, J. Chem. Phys., 9, 177 (1941).

26. J. M. Huang and F. C. Chang, J. Polym. Sci., Part B: Polym. Phys., 38, 934 (2000).

27. F. L. Binsbergen and B. G. M. DeLange, Polymer, 11, 309
(1970).

28. B. X. Fu, L. Yang, R. H. Somani, S. X. Zong, B. S. Hsiao, S. Phillips, R. Blanski, and P. Ruth, J. Polym. Sci., Part B: Polym. Phys., 39, 2727 (2001).

29. W. Nagatake, T. Takahashi, Y. Masubuchi, J. I. Takimoto, and K. Koyama, Polymer, 41, 523 (2000).

30. N. V. Pogodina, V. P. Lavrenko, S. Srinivas, and H. H. Winter, Polymer, 42, 9031 (2001). 